\title{
Investigating teachers' confidence on technological pedagogical and content knowledge: an initial validation of TPACK scales in K-12 computing education context
}

\author{
Michail N. Giannakos • Spyros Doukakis • \\ Ilias O. Pappas • Nikos Adamopoulos • \\ Panagiota Giannopoulou
}

Received: 1 September 2014/Revised: 18 November 2014/Accepted: 7 December 2014/

Published online: 25 December 2014

(C) Beijing Normal University 2014

\begin{abstract}
Computer science (CS) teachers' training and profile is crucial to ensure students have access to quality computer science education (CSE). The aim of this study is to examine the profile of CS teachers in Greece and map it using the technique of persona. This study examines a national sample of 636 CS teachers who teach algorithms and programing in upper secondary education. The building of the persona is based on teachers' abilities and needs regarding the central aspects of their knowledge with respect to three key domains as described by the technological, pedagogical, and content knowledge (TPACK) framework. According to the results, teachers attain relatively high scores on the TPACK subscales, however they state that there is an area for improvement in their Technology Knowledge and the intersection between content, pedagogical, and technological knowledge. In addition, teachers feel that they need further training on how to incorporate technology in their teaching as well as how to teach algorithms; which are two areas that relate to pedagogical content
\end{abstract}

\footnotetext{
M. N. Giannakos

Department of Computer and Information Science, Norwegian University of Science and

Technology (NTNU), Trondheim, Norway
}

M. N. Giannakos (

Sem Sælands vei 7-9, 7491 Trondheim, Norway

e-mail: michailg@idi.ntnu.no; michail.giannakos@idi.ntnu.no

S. Doukakis

The American College of Greece - Pierce, Athens, Greece

I. O. Pappas

Department of Informatics, Ionian University, Corfu, Greece

N. Adamopoulos

The Hellenic Ministry of Education, Athens, Greece

P. Giannopoulou

Leonteios Lyceum, Athens, Greece 
knowledge and TPACK. By mapping the knowledge, abilities, and needs of CS teachers, we will be able to recognize the challenges they face during teaching and consider strategies and policies for addressing these challenges.

Keywords Technological, pedagogical, and content knowledge $\cdot$ CS in schools . Teachers' training · Empirical experimentation $\cdot$ K-12 education $\cdot$ Personas

\section{Introduction}

Interest in computing has risen over the last decade and the subject is now often found as a distinct discipline in secondary education. Those living in the United States, the United Kingdom, New Zealand, South Korea, and Greece have seen a rise in activities and media focus on this topic (Wilson et al. 2010; The Royal Society 2012). This interest has generated a growing awareness in the efficacy of computing education in K-12 schools.

Computer science (CS) teachers in secondary education are required to have a broad knowledge of both computing and information communication technology (ICT). In addition, the Association for Computing Machinery (ACM) K-12 Educational Task Force (Tucker et al. 2011) advocates for teacher training programs that prepare the CS teachers with the necessary pedagogical skills to convey the information to the students at the appropriate level.

Authors of the Computer Science Teachers Association (CSTA 2013) report on CS teacher certification, advocate for the establishment of a Computer Science Praxis exam that will assess teachers' knowledge of CS concepts and the teachers' knowledge of pedagogy. Graham et al. (2009) posit that educators have come to realize that knowledge of how to use technological tools is not enough. Educators need to understand how to construct appropriate learning activities, to ensure that the students understand the concepts being taught, with technology effectively integrated into that learning process. Comments such as these have led several researchers (e.g., Doering et al. 2009; Mishra and Koehler 2006) to focus their studies on ways to integrate technological tools into teaching in a meaningful way.

Mishra and Koehler (2006) and Angeli and Valanides (2005) built upon Shulman's work (1987) to develop a framework combining three important aspects of teacher knowledge: pedagogical knowledge, content knowledge, and technological knowledge. The technological, pedagogical, and content knowledge (TPACK) framework is important for CS teachers as it helps them integrate technological tools effectively into their teaching practice. This is accomplished using the technological tools to learn the subject matter and facilitate the learning process (Mishra and Koehler 2006; Angeli and Valanides 2005).

The purpose of this empirical investigation is to measure CS teachers' knowledge regarding the components of TPACK and to map their profile. For this study, the researchers have used TPACK elements within a quantitative survey on a group of Greek CS teachers. The study itself had the two following objectives.

- Measure CS teachers' knowledge regarding: technology, pedagogy, and content

- Investigate CS teachers' abilities and needs 
The findings of these two objectives contribute to the identification of the challenges faced by CS teachers in the class and consider strategies and policies for addressing these challenges.

In the next section, the related work, the specific (Greek) educational context, and the technique of personas are outlined. The third section presents the methodology employed in this empirical study. The fourth section presents the research findings. Finally, the paper concludes with the implications, discusses the results, and the limitations of the research.

\section{Theoretical background and related work}

\section{TPACK framework and its use in CS}

Currently in the literature, there are two dominant theoretical models about the conceptualization of TPACK - the integrative model and the transformative model. The integrative model, as shown in Fig. 1 left, was proposed by Mishra and Koehler (2006), and it conceptualizes TPACK as an integrative body of knowledge defined by the intersections between content and pedagogy, content and technology, and pedagogy and technology. The transformative model (referred as ICT-TPCK), shown in Fig. 1 right, proposed by Angeli and Valanides $(2005,2009)$ conceptualizes technology, pedagogy, and content as a unique body of knowledge.

During the last years, TPACK framework has become a popular lens for studying teachers' knowledge and has been used in many recent studies on teachers (e.g., Syh-Jong and Kuan-Chung 2010; Ozgun-Koca et al. 2010; Han et al. 2013). Both frameworks (Fig. 1) are introduced by a Venn diagram to draw attention on how the TPACK can be separated, then how the intersections connect the different
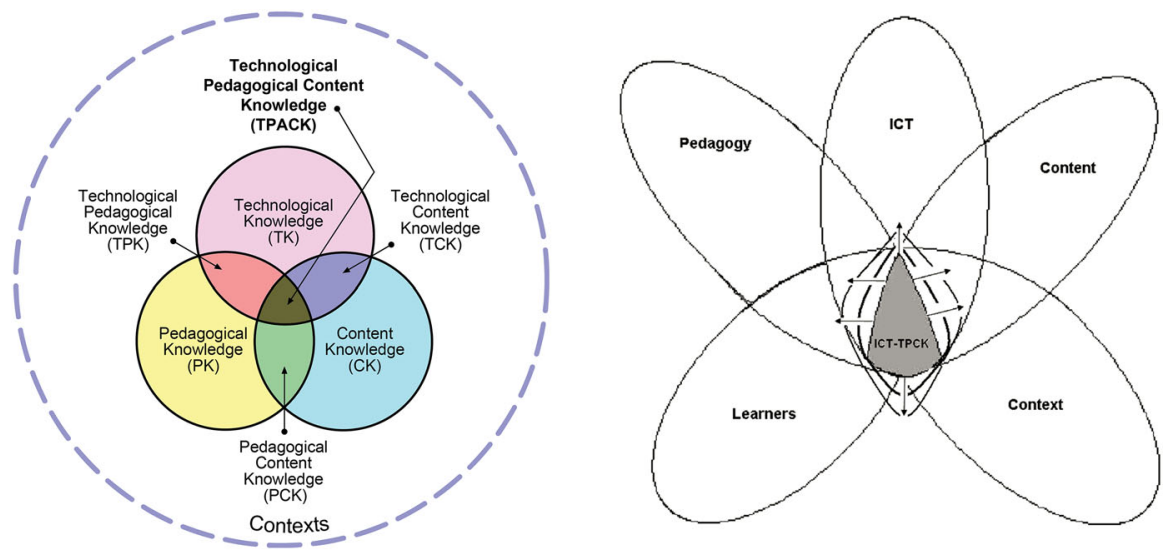

Fig. 1 The TPACK framework (reproduced by tpack.org (C) 2012); ICT-TPCK (reproduced by Angeli and Valanides 2009) 
knowledge areas. The center of the Venn diagram where the three knowledge components converge, is TPACK and ICT-TPCK, respectively, as it represents the TPACK as a cohesive whole, working and interacting together (Fig. 1). In other words, the teacher is able to understand and negotiate the complex relationships between the three knowledge areas.

The TPACK framework is made up of seven different knowledge components. There are the three unitary components of knowledge (content, pedagogy, and technology), three dyadic components of knowledge (pedagogical content, technological content, technological pedagogical) and one overarching triad (technological, pedagogical, and content knowledge). In 2010 Jimoyiannis (2010) adapted the pedagogical content knowledge (PCK) intersection to elucidate how it resembled for CS teachers:

- Content knowledge, for subject matter

- Knowledge and perceptions of the goals, objectives, means, and strategies of teaching CS at every level (knowledge of the curriculum)

- Knowledge of methods of understanding, perception, difficulties, and misunderstandings encountered by students in specific units of CS curriculum

- Knowledge of appropriate models of knowledge, available educational means, and effective teaching strategies for each unit

- Knowledge and perceptions about how to evaluate the scientific literature on CS and teaching approaches for CS

This provides the reader with a good example of how the knowledge strands can be woven together in a meaningful way.

The TPACK of in-service and pre-service teachers has been measured in both qualitative and quantitative studies revealing very prominent insights in many fields [e.g., mathematics and science (Doering et al. 2009; Schmidt et al. 2009; Niess 2005)]. However, although the TPACK (and its initial form of PCK) of CS teachers is considered highly important (Ioannou and Angeli 2013; Hubwieser et al. 2013; Ragonis and Hazzan 2009), few empirical studies have been conducted in this area. Therefore, the purpose of this paper is to measure the TPACK abilities of secondary CS teachers and use this information to determine the abilities and needs of those teachers. This will help inform those who design CS teacher training programs.

Computing education in Greece

\section{Content knowledge (CK)}

In Greece, the teaching of CS in secondary education is conducted by teachers holding an undergraduate degree in CS, computer engineering, or applied informatics. Secondary education in Greece is divided into two cycles: compulsory lower secondary and non-compulsory upper secondary education. Compulsory lower secondary education is provided in Gymnasium (middle school), while noncompulsory upper secondary education is taken in one of two types of Lyceums (high schools): the General Lyceum and Vocational Lyceum. 
The first grade of General Lyceum represents an orientation year with a general education program. The second and third grades offer three curricular directions: theoretical, scientific, and technological. Students who follow the technological direction take a specific course named Applications Development in a Programming Environment (hereinafter the CS or Informatics course), that involves the development of algorithms and programing. This course has been taught for 15 years (since 1999). It focuses on the algorithmic approach and on the development of problem-solving skills in a programing environment. This subject is assigned to CS teachers and this examination is at national level and is considered when selecting students for admission in higher education programs.

The overall aim of the third grade of Lyceum CS courses is to develop analytical and synthetic thinking, acquire methodological skills, and be able to solve simple problems within a programing environment. This course has not been designed to educate programmers, and for this reason it is not designed to teach sophisticated programing techniques; it focuses on approaches and techniques of problem solving with emphasis on structured thinking. Many basic algorithmic and programing concepts, such as conditions, expressions, and logical reasoning, are fundamentals of general knowledge and skills to be acquired in general education (Eyrydice 2009).

\section{Technological knowledge (TK)}

The curriculum states that this subject must be taught (at least partially) in a computer lab. The Ministry of Education has certified specific Educational Software to support the lab work, especially for the Lyceum CS course. The Educational Software has been designed to support teaching, to complement the subject's needs and IT use and to help students to consolidate the material. The certified software includes an activity space, a flow chart developer, and a programing environment in accordance with the textbook.

The use of personas

Persona is an archetype of actual characters (e.g., users, students, and teachers) with well-defined attributes and it was first introduced in HCI community by Cooper (1999). Personas technique creates fictitious characters called personas; this technique portraits the target character on whom capabilities and efforts should focus. Persona is a powerful and multi-purpose analysis technique that can help designers, educators, and software engineers to identify the functionalities and capabilities of the target audience, by taking into account their needs and goals (Chang et al. 2008). These imaginary characters must be defined according to data retrieved from initial investigation of the target character.

Researchers argue that people more easily remember people's profiles than technical reports. Furthermore, personas act as a mechanism to enhance attention and help in the organization of data (Hakulinen et al. 2008) carried out during the design phase of a product, curriculum, or policy. 
Building the persona of CS teachers will help CS subjects in diverse ways. For example, the curriculum designer might wonder, "Are CS teachers able to use sophisticated technological tools?" or "Do CS teachers need regular training?" The data collected from building the Personas will provide responses to these questions as they will help us identify the challenges and needs CS teachers face and train them (e.g., with certification program) appropriately.

\section{Methodology}

\section{Context}

The empirical study was conducted in the context of the Greek educational system and in particular based on the CS teachers of the upper secondary education (with students from 16 to 18 years old). The CS teachers in Greece hold, at minimum, an undergraduate degree in CS, computer engineering, informatics, or applied informatics. Their teaching responsibilities are to teach CS and technology as described in detail within section three. As such, our sample consisted of experienced CS teachers and they were asked about their knowledge and experience regarding the attributes we were investigating.

\section{Sampling}

The final sample of respondents comprised 636 CS teachers who have taught the main CS course of high school, named Applications Development in a Programming Environment. From the total sample, $66.4 \%$ were male teachers and $96 \%$ were under 50 years old. The majority of teachers $(61 \%)$ had an undergraduate degree, while $35 \%$ had a postgraduate degree, and the remainder had a doctoral degree.

\section{Measures}

The questionnaire consisted of 25 questions about TPACK, adopted from Schmidt et al. (2009); the questionnaire items are exhibited in the Appendix. All questions were related to the three key domains as described by the TPACK framework (technology, pedagogy, content, and the combination of these areas). The 25 questions in the questionnaire were divided into questions about technological knowledge (TK) (3 questions), content knowledge (CK) (four questions), pedagogical knowledge (PK) (four questions), PCK (two questions), technological content knowledge (TCK) (three questions), technological pedagogical knowledge (TPK) (four questions), and technological pedagogical content knowledge (TPACK) (three questions). The responses to each question were measured using a five-point Likert scale where 1 stands for 'strongly disagree', and 5 stands for 'strongly agree'. For each subscale the participant's responses were averaged. Furthermore, the questionnaire included ten questions that provided demographic data. The participants completed the questionnaire in the middle of the school year, having 
covered the appropriate material for all basic algorithmic components (sequential structure, conditional structure, and loops). The respondents came from the 13 regions of Greece. The sample was representative of the population of educators of CS by region.

\section{Data analysis}

The first step of our analysis is to conduct a confirmatory factor analysis in order to explore the adequacy of fit of the seven factors. Goodness of fit (GoF) describes how well the seven factors (model) fit the data. . The Chi-square statistic is sensitive to sample size, and is expected to be above the recommended value of three because of the large sample of this study. However as a global statistic it is used in this study. Several fit indices were used to assess model-data fit. Root mean square error of approximation (RMSEA), normed fit index (NFI), comparative fit index (CFI), and $\chi^{2} / \mathrm{df}$ ratio were all used to evaluate model-data fit (Byrne 2009). RMSEA less than 0.05 suggests good model-data fit; and between 0.05 and 0.08 suggests acceptable model-data fit. CFI and TLI indices greater than 0.90 suggest good model-data fit.

In this study, AMOS 18.0 was employed for the confirmatory factor analysis, based on Byrne (2009). The model tested in this study was estimated using maximum likelihood estimation (MLE) where all analyses were conducted on variance-covariance matrices. The seven factors in this study were assumed to be correlated and allowed to covary in the model. In addition, the measurement model was a congeneric model in which each indicator only loads on one of the seven factors and all measurement errors were assumed to be uncorrelated.

Subsequently, descriptive statistics of the measurement attributes and the demographics, education, and experience of the respondents were applied. In the next step, we used the results of the descriptive statistics to categorize our data (e.g., demographics, teacher needs, TPACK attributes) and via empirical data mapping we determined the persona of the CS teacher.

Table 1 Pearson's correlation coefficient between TPACK attributes $(n=636)$

\begin{tabular}{lllllll}
\hline & CK & PK & TK & PCK & TCK & TPK \\
\hline CK & - & - & - & - & - & - \\
PK & 0.51 & - & - & - & - & - \\
TK & 0.20 & 0.23 & - & - & - & - \\
PCK & 0.51 & 0.43 & 0.23 & - & - & - \\
TCK & 0.75 & 0.56 & 0.16 & 0.51 & 0.48 & - \\
TPK & 0.46 & 0.36 & 0.19 & 0.75 & 0.47 & 0.70 \\
TPACK & 0.51 & 0.42 & 0.26 & 0.62 & 0 \\
\hline
\end{tabular}

Correlations are significant at the 0.01 level. $C K$ content knowledge; $P K$ pedagogical knowledge; $T K$ technological knowledge; $P C K$ pedagogical content knowledge; $T C K$ technological content knowledge; $T P K$ technological pedagogical knowledge; TPACK technological pedagogical content knowledge 
Table 2 Results of the confirmatory analysis $(n=636)$

\begin{tabular}{|c|c|c|c|c|c|c|}
\hline Item & Statement & Mean (SD) & $\mathrm{CR}$ & $R^{2}$ & SE & $\alpha$ \\
\hline \multicolumn{2}{|c|}{ Content knowledge (CK) } & $4.16(0.55)$ & - & & & 0.78 \\
\hline CK1 & I can use a computational way of thinking & $4.23(0.71)$ & 13.9 & 0.42 & 0.642 & - \\
\hline CK2 & $\begin{array}{l}\text { I have various ways and strategies of developing } \\
\text { my understanding of Informatics* }\end{array}$ & $4.04(0.72)$ & 15.2 & 0.51 & 0.711 & - \\
\hline CK3 & I have sufficient knowledge about Informatics* & $4.22(0.70)$ & 15.2 & 0.51 & 0.712 & - \\
\hline CK4 & $\begin{array}{l}\text { I know about various examples of how } \\
\text { Informatics* applies in the real world }\end{array}$ & $4.14(0.72)$ & $-{ }^{\mathrm{a}}$ & 0.43 & 0.653 & - \\
\hline \multicolumn{2}{|c|}{ Pedagogical knowledge (PK) } & $4.31(0.55)$ & - & & & 0.71 \\
\hline PK1 & $\begin{array}{l}\text { I can adapt my teaching based upon what students } \\
\text { currently understand or do not understand }\end{array}$ & $4.20(0.71)$ & 11.6 & 0.36 & 0.597 & - \\
\hline PK2 & $\begin{array}{l}\text { I know how to assess student performance in a } \\
\text { classroom }\end{array}$ & $4.49(0.65)$ & 12.6 & 0.46 & 0.680 & - \\
\hline PK3 & $\begin{array}{l}\text { I am familiar with common student understandings } \\
\text { and misconceptions }\end{array}$ & $4.23(0.74)$ & $-{ }^{\mathrm{a}}$ & 0.42 & 0.650 & - \\
\hline \multicolumn{2}{|c|}{ Technological knowledge (TK) } & $3.41(1.21)$ & - & & & 0.70 \\
\hline TK1 & I know how to use technologies & $2.95(1.40)$ & 6.28 & 0.38 & 0.616 & - \\
\hline TK2 & I know about a lot of different technologies & $3.87(1.31)$ & $-{ }^{\mathrm{a}}$ & 0.61 & 0.783 & - \\
\hline \multicolumn{2}{|c|}{ Pedagogical content knowledge (PCK) } & $4.01(0.59)$ & - & - & - & 0.77 \\
\hline PCK1 & $\begin{array}{l}\text { I am capable to organize and maintain classroom } \\
\text { management to guide student thinking and } \\
\text { learning informatics* }\end{array}$ & $4.07(0.70)$ & 16.5 & 0.51 & 0.717 & - \\
\hline PCK2 & $\begin{array}{l}\text { I know how to select effective teaching approaches } \\
\text { to guide student thinking and learning } \\
\text { informatics* }\end{array}$ & $4.04(0.66)$ & $-{ }^{\mathrm{a}}$ & 0.50 & 0.707 & - \\
\hline \multicolumn{2}{|c|}{ Technological content knowledge (TCK) } & $4.11(0.56)$ & - & & & 0.72 \\
\hline TCK1 & $\begin{array}{l}\text { I know about technologies that I can use for } \\
\text { understanding and doing Informatics* }\end{array}$ & $4.13(0.79)$ & 13.1 & 0.45 & 0.672 & - \\
\hline TCK2 & $\begin{array}{l}\text { I can select technology to guide student thinking } \\
\text { and learning in Informatics* }\end{array}$ & $4.23(0.64)$ & $-{ }^{\mathrm{a}}$ & 0.30 & 0.549 & - \\
\hline TCK3 & $\begin{array}{l}\text { I know how to using technology to change the way } \\
\text { students understand informatics* concepts. }\end{array}$ & $3.96(0.72)$ & 12.9 & 0.49 & 0.696 & - \\
\hline \multicolumn{2}{|c|}{ Technological pedagogical knowledge (TPK) } & $4.18(0.54)$ & - & & & 0.78 \\
\hline TPK1 & $\begin{array}{l}\text { I can adapt the use of the technologies that I am } \\
\text { learning about to different teaching activities }\end{array}$ & $4.21(0.71)$ & 17.8 & 0.51 & 0.711 & - \\
\hline TPK2 & $\begin{array}{l}\text { I am thinking critically about how to use } \\
\text { technology in my classroom }\end{array}$ & $4.16(0.72)$ & 13.4 & 0.30 & 0.548 & - \\
\hline TPK3 & $\begin{array}{l}\text { I can choose technologies that enhance the teaching } \\
\text { approaches for a lesson }\end{array}$ & $4.18(0.67)$ & 19.7 & 0.61 & 0.783 & - \\
\hline TPK4 & $\begin{array}{l}\text { I can choose technologies that enhance students' } \\
\text { learning for a lesson }\end{array}$ & $4.19(0.68)$ & $-{ }^{\mathrm{a}}$ & 0.57 & 0.754 & - \\
\hline \multicolumn{2}{|c|}{ Technological pedagogical content knowledge (TPACK) } & $4.03(0.66)$ & - & & & 0.84 \\
\hline TPACK1 & $\begin{array}{l}\text { I can teach lessons that appropriately combine } \\
\text { informatics*, technologies, and teaching } \\
\text { approaches }\end{array}$ & $4.09(0.78)$ & 19.4 & 0.55 & 0.742 & - \\
\hline TPACK2 & $\begin{array}{l}\text { I can select technologies to use in my classroom } \\
\text { that enhance what I teach, how I teach, and what } \\
\text { students learn }\end{array}$ & $4.03(0.77)$ & 23.0 & 0.76 & 0.872 & - \\
\hline
\end{tabular}


Table 2 continued

\begin{tabular}{|c|c|c|c|c|c|c|}
\hline Item & Statement & Mean (SD) & $\mathrm{CR}$ & $R^{2}$ & SE & $\alpha$ \\
\hline TPACK3 & $\begin{array}{l}\text { I can teach lessons that appropriately combine the } \\
\text { content of Informatics*, technology and teaching } \\
\text { approaches }\end{array}$ & $3.96(0.72)$ & $-^{\mathrm{a}}$ & 0.62 & 0.790 & - \\
\hline
\end{tabular}

$\overline{\text { * Informatics refer to the rigorous } C S \text { course; } C R \text { critical ratio; } S E \text { standardized estimate; } \alpha \text { Cronbach's }}$ alpha

${ }^{a}$ This value was fixed at 1.00 for model identification purposes

\section{Research findings}

The correlations among each of the attributes were examined using Pearson correlations. Pearson's correlation coefficient between the factors was used, which quantifies the strength of the relationship between the variables. Pearson's test suggests all the factors are relatively strong related. In particular, the correlation coefficients between the attributes varied from 0.16 (TK and TCK) to 0.75 (CK and TCK), can be seen in detailed in Table 1.

Table 2 shows the CFA results of the 21-item, seven-factor scale. Each item was specified to load on just one factor in the model, so the standardized estimates were regarded as structure coefficients that estimate indicator-construct correlations (Byrne 2009). For each of the seven sets of items, the standardized estimates were relatively large (0.549-0.872), which provided support for convergent validity (Maruyama 1998). Evidence for discriminant validity was also strong based on the inter-factor correlations $(r=0.19-0.75)$ (Table 1$)$, which should not exceed 0.8 points, as this would suggest low discrimination. From Table 2, all standardized estimates were statistically significant at the $p<0.001$ level and exceeded the recommended value of 0.50 (Hair et al. 2010). The Cronbach's alpha for each of the four factors met the recommended level for instrument development, which needs to be higher than 0.7 for every factor and this provided support for the factorial and construct validity of the model. The results revealed an acceptable model fit $\left[x^{2} / d f=3.65, \mathrm{TLI}=0.901 ; \mathrm{CFI}=0.921 ; \mathrm{RMSEA}=0.065\right]$. Figure 2 shows the graphic representation of the 21-item, seven-factor model.

The first attribute, content knowledge (CK), refers to the knowledge teachers must have regarding CS. CS teachers' CK is shown to be quite high (Mean = 4.16) with good item loadings and Cronbach's alpha value (Table 2). This suggests that teachers had a high $\mathrm{CK}$, such as feeling confident for their knowledge on algorithmic and problem-solving concepts, which dominates the CS subject.

The second attribute, pedagogical knowledge (PK) is rated higher than the other cognitive subscales. The high average implies that CS teachers have deep knowledge of the educational process and methodology of teaching and learning, and thus can achieve the aim of the subject.

The third attribute, technological knowledge (TK) is also found to be quite high. According to Mishra and Koehler (2006), TK is associated with the ability to 


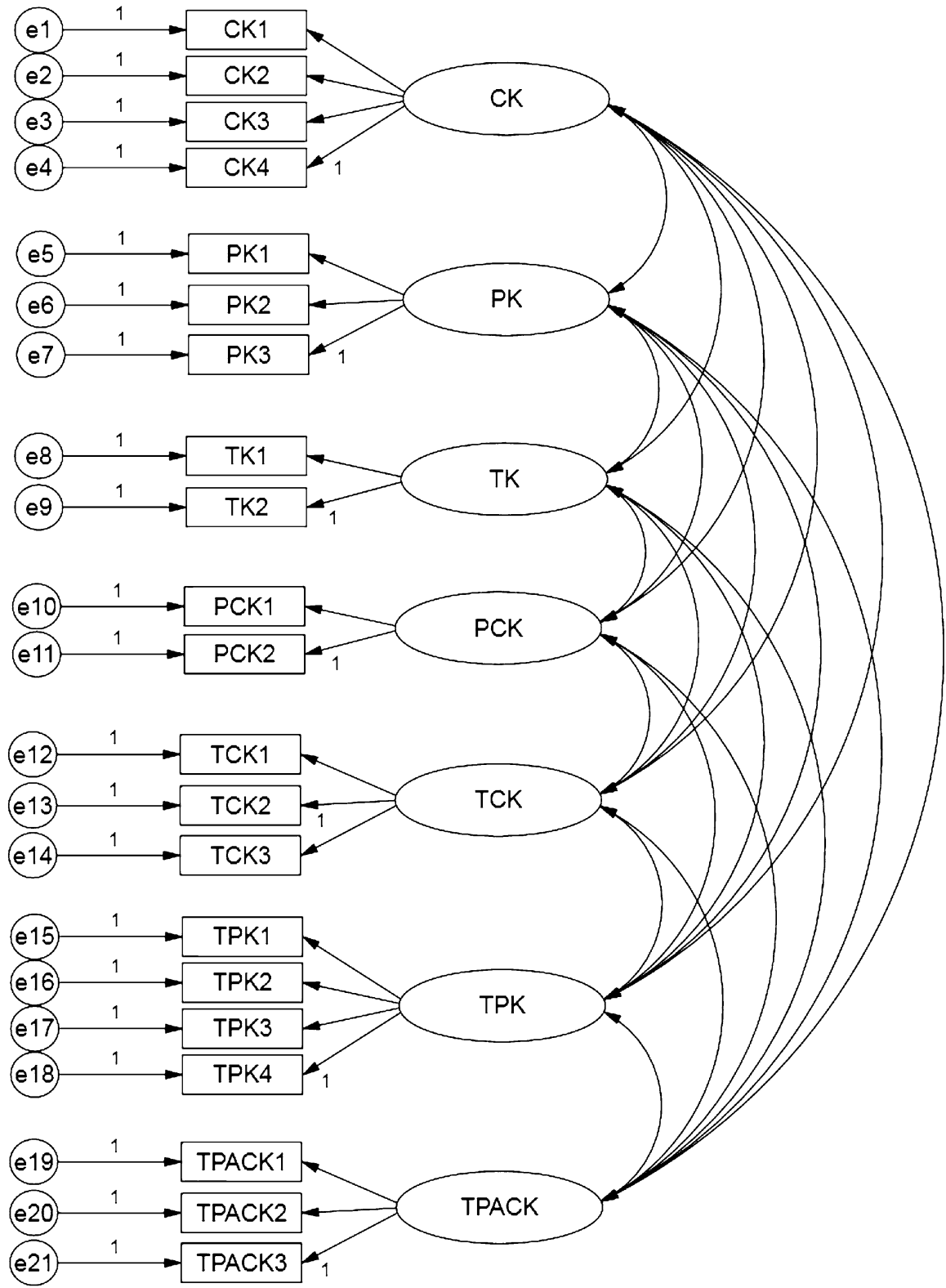

Fig. 2 Graphical representation of the 21-item, seven-factor model

manipulate the technological tools and also the knowledge on how to use the technology with others. This is also reflected in questions concerning the type of training, teachers consider as necessary. A small percentage (37\%) of the respondents reported that they needed training in educational software to support the lab work. 
The dyadic attribute of PCK shows that, even if teachers of CS had both pedagogical knowledge and deep knowledge of their subject matter, they seem to be less confident in transforming and applying effectively their content knowledge to their teaching practice (Shulman 1987).

For the technological content knowledge (TCK) attribute, it seems that teachers rate themselves lower than their content understanding. Therefore, teachers seemed to need assistance to comprehend how the use of technology affects and can be integrated with technology. This is also reflected in questions concerning the type of training they consider necessary, where $70 \%$ of the respondents needed training in methods to integrate educational software in their teaching practice.

According to their responses, CS teachers seem to exhibit very high technological pedagogical knowledge $(\mathrm{TPK}$, mean $=4.18)$. This shows that educators have realized that teaching and learning are altered when using specific technological tools. This knowledge includes awareness of their tools' restrictions and affordances in designing pedagogical strategies.

Finally, the score in the intersection between content, pedagogy, and technology (TPACK, mean $=4.03$ ) shows that teachers are aware of the intersection between content, pedagogy, and technology. Thus, it appears that teachers enhance teaching with a unique combination, a dynamic equilibrium, between the three teaching components (pedagogy, content, and technology).

At the time of the study, the majority $(76 \%)$ of the respondents had more than 3 years of teaching experience of CS in schools. The average mean for all items was 4.05. The range of response was 4 , with a minimum response of 1 , a maximum response of 5, and a standard deviation of 0.81 . In particular, respondents expressed very high knowledge on PK (4.38/5), and slightly lower on CK, TCK, and TPK (4.11-4.16/5). Also, respondents expressed positively for their TK (4.09/5), PCK $(4.06 / 5)$, and the intersection between content, pedagogy, and technology (TPACK) $(4.03 / 5)$.

In order to map the knowledge, the abilities, and the needs of CS teachers we developed their persona. Using the persona technique, we created a fictional teacher, named Greek CS teacher (Fig. 3). The data extracted from our study were the starting point to create that fictional teacher, where his characteristics were based on real data from the teachers, who have participated in our study. The created character was based on an aggregated set of characteristics from several participants in the study.

Specifically, the persona consisted of the demographics, education, and experience of the teacher and his needs and level of TPACK attributes (Fig. 3). An interesting finding was that $54 \%$ of the teachers who took part in the research claimed that they needed training in order to properly teach the CS courses. In particular, $70 \%$ of the CS teachers reported that they needed to be trained in how to incorporate the course educational software in their teaching. $43 \%$ wish to be trained in how to teach algorithms, while $37 \%$ agreed that they needed training in using the educational software of their courses.

Based on the results, more than half of the teachers wish to be trained for the CS course and more particularly in pedagogy, technology, and the integration of 


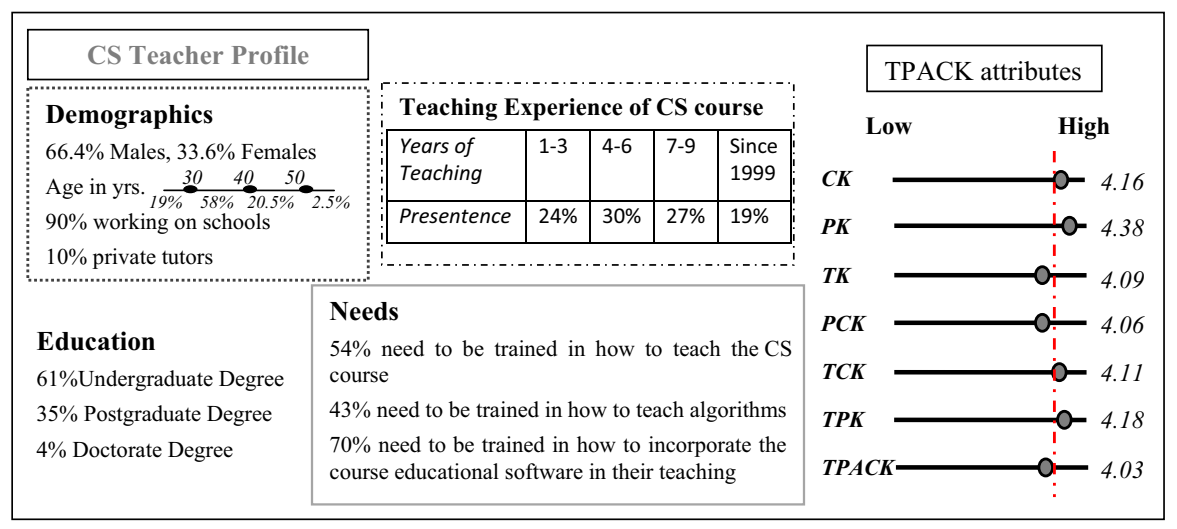

Fig. 3 CS teacher persona based on the collected data

technology in their teaching practice. On the other hand, the other half of the teachers do not wish to be further trained.

Despite the fact that CS teachers claim to possess the above attributes, it seems that only $62 \%$ of them are making use of the technological tools and the computer laboratory, while $38 \%$ teach the subject exclusively in the classroom. Out of the $62 \%$ of teachers who use technological tools and the laboratory, $65 \%$ consider that conducting sessions in the laboratory reduces the time needed to cover the curriculum. However, they use technological tools mostly to present algorithmic issues $(41 \%)$ and less for students to practice with the available tools and relevant training scenarios $(31 \%)$.

\section{Discussion and conclusions}

In this empirical study, CS teachers' knowledge and needs were examined. In particular, we measured CS teachers' TPACK attributes and their needs in regard of teaching CS. The levels of TPACK attributes are relatively high among teachers (4.02-4.38).

In particular, according to the results in the seven subscales, teachers state that their knowledge is between the values 4.38 (PK) and 4.09 (TK). Moreover, it seems that the teachers who teach the course wish to be trained in how to incorporate educational software in their teaching practice so as to improve their TCK as well as their overall TPACK. This leads us to conclude that teachers want to be able to determine when technology contributes and when it obstructs the teaching of CS. Therefore, it seems that teachers need that support, which will help them judge and evaluate how technology affects their lessons. Teachers' high degree of independence in TPK indicates that they are capable of evaluating the consequences technology has on teaching and learning, but they are not ready to determine the ways technology affects teaching and learning. As a result, it is important for 
teachers to acquire the experience that will allow them to distinguish those technological tools that are more appropriate to support specific cognitive goals during the development of algorithm. It will also allow them to know how the content of their course can determine or modify the technology in use.

The curricula for computer science education (CSE) of many countries comprise both ICT and rigorous CS (e.g., programing, algorithms). However, during the last few years, the focus of CSE in K-12 education has shifted from computer and ICT applications toward rigorous computing in several countries or states (Hubwieser et al. 2011, 2014). Accordingly, the students should learn basic concepts of CS like algorithms or data structures instead of mere user skills. In many places, initiatives and projects were launched to foster this change. For example, in USA the activities of the CSTA yielded quite ambitious standards in 2011 (Tucker et al. 2011) and a disclosing comparison of CSE over the 50 states in 2010. In German and Greek school contexts, studies have shown that these two areas (ICT as a tool and CS as a content) have substantial differences (Giannakos et al. 2013) and should be treated differently. As such, the need for investigating ICT (TK in our case) and CS skills (CK in our case) differently is an emerging need and our study sheds light on this need backed on empirical data retrieved from a large scale study of a rigorous CS course.

Finally, teacher preference for training in matters of teaching algorithms indicates that even though teachers have (a) pedagogical knowledge and (b) very good knowledge of their subject, they claim that they are less capable of transforming and effectively applying their knowledge for teaching. Thus, it could be claimed that there is a need to train teachers so they will be able to identify the most common student misconceptions, as well as to be able to find ways to overcome them.

The above results may prove very useful in the design of future training programs for CS teachers in general and, in particular, in Greece. According to these results, teachers are in search of a teaching framework that is far removed from the conventional classroom and which will incorporate more use of the laboratory, something that is in compliance with the nature of the course, too. Despite the fact that CS teachers are the ones with the greatest experience and knowledge regarding computer use, it seems that they prefer to be trained with the incorporation of technological tools in their teaching. Nonetheless, special attention should be given to the development of appropriate educational scenarios and examples that will contribute to the improvement of student learning as well as of the teacher work.

As with any empirical study, there are some limitations. First, in this study the respondents are Greek CS teachers, who are part of the Greek educational system; this may limit the generalization of the findings. However, Greek CS undergraduate degree (which is the precondition for CS teachers) conform to the international standards (ACM 2002). Second, the data are based on self-reported method; other methods such as depth interviews and observations could have provided a complementary picture of the findings through data triangulation.

These are the first efforts to develop the profile of CS teachers based on empirical data. Future studies with empirical data from different countries of Europe and US with different educational systems' and CS curricula using wide variety of measures 
(i.e., observations, interviews) will allow us to better understand and map CS teachers' knowledge and needs. Currently, the authors are preparing a series of interviews with experts (experienced CS teacher, CS teacher trainers, and supervisors) in order to extend academic knowledge in understanding CS teachers' knowledge.

Acknowledgments The authors wish to thank all the CS teachers who kindly spent their time and expertise.

\section{Appendix: Survey items within each of the seven TPACK subscales}

Technology knowledge (TK)

- I know how to use technologies

- I know about a lot of different technologies*

- I have the technical skills I need to use technology

Content knowledge (CK)

- I can use a computational way of thinking

- I have various ways and strategies of developing my understanding of "Informatics"**

- I have sufficient knowledge about "Informatics"

- I know about various examples of how "Informatics" applies in the real world

Pedagogical knowledge (PK)

- I know when it is appropriate to use a variety of teaching approaches in a classroom setting (collaborative learning, direct instruction, inquiry learning, problem/project-based learning, etc.)*

- I can adapt my teaching based upon what students currently understand or do not understand

- I know how to assess student performance in a classroom

- I am familiar with common student understandings and misconceptions

- I know how to organize and maintain classroom management*

Pedagogical content knowledge (PCK)

- I am capable to organize and maintain classroom management to guide student thinking and learning "informatics"

- I know how to select effective teaching approaches to guide student thinking and learning "informatics"

- I know that different computational concepts do not require different teaching approaches* 


\section{Technological content knowledge (TCK)}

- I know about technologies that I can use for understanding and doing "Informatics"

- I can select technology to guide student thinking and learning in "Informatics"

- I know how to using technology to change the way students understand "informatics" concepts

Technological pedagogical knowledge (TPK)

- I can adapt the use of the technologies that I am learning about to different teaching activities

- I am thinking critically about how to use technology in my classroom

- I can choose technologies that enhance the teaching approaches for a lesson

- I can choose technologies that enhance students' learning for a lesson

\section{Technological pedagogical content knowledge (TPACK)}

- I can teach lessons that appropriately combine "informatics", technologies, and teaching approaches

- I can select technologies to use in my classroom that enhance what I teach, how I teach, and what students learn

- I can teach lessons that appropriately combine the content of "Informatics", technology and teaching approaches

* Deleted due to low factor loadings

** Informatics refer to the rigorous CS course

\section{References}

Angeli, C., \& Valanides, N. (2005). Preservice teachers as ICT designers: An instructional design model based on an expanded view of pedagogical content knowledge. Journal of Computer-Assisted Learning, 21(4), 292-302.

Angeli, C., \& Valanides, N. (2009). Epistemological and methodological issues for the conceptualization, development, and assessment of ICT-TPCK: Advances in technological pedagogical content knowledge (TPCK). Computers \& Education, 52(1), 154-168.

Byrne, B. (2009). Structural equation modeling with AMOS: Basic concepts, applications, and programming., Multivariate applications book series New York: Taylor \& Francis.

Chang, Y., Lim, Y., \& Stolterman, E. (2008). Personas: From theory to practices. Proceedings of the Nordic Conference on Human-Computer Interaction (NordiCHI'08) (pp. 439-442). New York: ACM.

Cooper, A. (1999). Design von Informationswelten, Gemeinsame Fachtagung des German Chapter of the ACM, der Gesellschaft für Informatik (GI) und der SAP AG, 17. Teubner.

CSTA Report. 2013. Bugs in the system: Computer science teacher certification in the U.S. The Computer Science Teachers Association. Retrieved from http://csta.acm.org/ComputerScienceTeacherCertific ation/sub/CertificationResources.html.

Doering, A., Scharber, C., Miller, C., \& Veletsianos, G. (2009). GeoThentic: Designing and assessing with technological pedagogical content knowledge. Contemporary Issues in Technology and Teacher Education, 9(3), 316-336. 
Eyrydice. (2009). Organisation of the education system in Greece (2008/2009). Retrieved from http:// eacea.ec.europa.eu/education/eurydice.

Giannakos, M., Hubwieser, P., \& Chrisochoides, N. (2013). How students estimate the effects of ICT and programming courses. Proceedings of the 44th ACM Technical Symposium on Computer Science Education (pp. 717-722). New York: ACM.

Graham, C. R., Burgoyne, N., Cantrell, P., Smith, L., St. Clair, L., \& Harris, R. (2009). TPACK development in science teaching: Measuring the TPACK confidence of inservice science teachers. TechTrends, 53(5), 70-79.

Hair, J. F., Tatham, R. L., Anderson, R. E., \& Black, W. (2010). Multivariate data analysis (7th ed.). Upper Saddle River, NJ: Pearson Prentice Hall.

Hakulinen, J., Turunen, M., Smith, C., Cavazza, M., Charlton, D. (2008). A model for flexible interoperability between dialogue management and domain reasoning for conversational spoken dialogue systems. In Proceedings of the 4th International Workshop on Human-Computer Conversation (pp. 29-34).

Han, I., Eom, M., \& Shin, W. S. (2013). Multimedia case-based learning to enhance pre-service teachers' knowledge integration for teaching with technologies. Teaching and Teacher Education, 34(2), 122-129.

Hubwieser, P., Armoni, M., Giannakos, M. N., \& Mittermeir, R. T. (2014). Perspectives and visions of computer science education in primary and secondary (K-12) Schools. ACM Transactions on Computing Education (TOCE), 14(2), 7.

Hubwieser, P., Armoni, M., et al. (2011). Computer science/informatics in secondary education. Proceedings of the 16th ITiCSE-WGR'11 (pp. 19-38). New York: ACM.

Hubwieser, P., Magenheim, J., Mühling, A., \& Ruf, A. (2013). Towards a conceptualization of pedagogical content knowledge for computer science. Proceedings of the Ninth Annual International ACM Conference on International Computing Education Research (ICER'13) (pp. 1-8). New York: ACM.

Ioannou, I., \& Angeli, C. (2013). Teaching computer science in secondary education: A technological pedagogical content knowledge perspective. Proceedings of the 8th Workshop in Primary and Secondary Computing Education (pp. 1-7). New York: ACM.

Jimoyiannis, A. (2010). Designing and implementing an integrated technological pedagogical science knowledge framework for science teachers professional development. Computers \& Education, 55(3), 1259-1269.

Maruyama, G. M. (1998). Basics of structural equation modeling. London: Sage.

Mishra, P., \& Koehler, M. J. (2006). Technological Pedagogical Content Knowledge: A new framework for teacher knowledge. Teachers College Record, 108(6), 1017-1054.

Model Curriculum and Guidelines for Undergraduate Degree Programs in Information Systems. (2002). Retrieved from http://www.acm.org/education/is2002.pdf.

Niess, M. L. (2005). Preparing teachers to teach science and mathematics with technology: Developing a technology pedagogical content knowledge. Teaching and Teacher Education, 21(5), 509-523.

Ozgun-Koca, S. A., Meagher, M., \& Todd, E. M. (2010). Preservice teachers' emerging TPACK in a technology-rich methods class. Mathematics Educator, 19(2), 10-20.

Ragonis, N., \& Hazzan, O. (2009). Integrating a tutoring model into the training of prospective computer science teachers. Journal of Computers in Mathematics and Science Teaching, 28(3), 309-339.

Schmidt, D., Baran, E., Thompson, A., Koehler, M. J., Shin, T., \& Mishra, P. (2009). Technological pedagogical content knowledge (TPACK): The development and validation of an assessment instrument for preservice teachers. Journal of Research on Technology in Education, 42, 123-149.

Shulman, L. S. (1987). Knowledge and teaching: Foundations of the new reform. Harvard Educational Review, 57(1), 1-22.

Syh-Jong, J., \& Kuan-Chung, C. (2010). From PCK to TPACK: Developing a transformative model for pre-service science teachers. Journal of Science Educational Technology, 19, 553-564.

The Royal Society. (2012). Shutdown or restart. The way forward for computing in UK schools. Retrieved August 29, 2014, from http://royalsociety.org/uploadedFiles/Royal_Society_Content/ education/policy/computing-in-schools/2012-01-12-Computing-in-Schools.pdf.

Tucker, A., Seehorn, D., Carey, S., et al. (2011). CSTA K-12 computer science standards. New York: CSTA Standards Task Force.

Wilson, C., Sudol, L. A., Stephenson, C., \& Stehlik, M. (2010). Running on empty: The failure to teach k-12 computer science in the digital age. New York: The Association for Computing Machinery (ACM) and the Computer Science Teachers Association (CSTA). Retrieved December 19, 2014, from http://www.acm.org/Runningonempty/. 
Michail N. Giannakos is an Associate Professor at the Department of Computer and Information Science, Norwegian University of Science and Technology (NTNU). His research interests focus on the design and study of emerging technologies and pedagogies in online and hybrid education settings. His research interests center on making sense of users experiences and practices in order to redesign and optimize the education settings and systems. His goal is to understand why and how learners and scholars use technologies in the ways that they do. He has developed and experimented with learning environments since 2008, and since that time has single- or co-authored more than sixty manuscripts published in peer-reviewed journals and conferences. He has worked at several research projects funded by diverse sources like EC, Microsoft Research, NSF, and Cheng Endowment; he is also a recipient of an ERCIM/Marie Curie fellowship.

Spyros Doukakis holds a PhD in Mathematics Education from the University of the Aegean, Greece. He is a secondary education teacher of Mathematics and Computer Sciences at PIERCE - The American College of Greece, an e-tutor of Mathematics and visiting lecturer at School of Pedagogical \& Technological Education (ASPETE). He was awarded the Harvard Club 2014 "Excellence in Teaching" award from the Harvard Club of Boston. He is a certified teacher's trainer in pedagogical issues, mathematics, computers and use of digital technologies He has participated in several research projects and has published many articles in journals and international conferences. He is the co-author of several books about Computer Sciences and Mathematics.

Ilias O. Pappas received his BSc in Informatics (specialization in Humanities Informatics) from the Ionian University, Corfu, Greece and an MSc degree in Informatics (specialization in Information Systems) from the same university. He is currently working on a $\mathrm{PhD}$ degree at the Ionian University. His current research interests are in the areas of information technology adoption, user behavior in online environments, personalization and recommendation agents, and customer emotions in the Internet marketing. He has published articles in international journals and international conferences including Electronic Markets and International Journal of Retail and Distribution Management.

Nikos Adamopoulos holds a Diploma in Computer Engineering and Informatics, as well as an MSc in Computer Science and Engineering - University of Patras, Greece. He also holds a Certificate of Pedagogical and Teaching Competence from the School of Pedagogical and Technological Education ASPETE. He is an Informatics teacher at the Primary and Secondary Education of Greece. His research interest included teaching algorithms, educational robotics and adult education.

Panagiota Giannopoulou is a secondary education teacher of Computer Science at Leonteios Lyceum Patission. She holds a MSc in Applied Mathematics and two Bachelor's degree in Mathematics and Computer Sciences. She is the co-author of two books about Computer Sciences. Her research interest included teaching algorithms and programming. 